\title{
Convulsive syncope: a Stokes-Adams case
}

\author{
Síncope convulsivo: un caso de Stokes-Adams \\ Laura CAIRE-HERRERA', Enrique GOMEZ-FIGUEROA², Roberto CERVANTES-URIBE², \\ Ramiro ROSAS-GUTIERREZ3 ${ }^{3}$ Álvaro MORENO-AVELLAN³, Maricarmen FERNÁNDEZ3
}

A 26-year-old male with two-days prior cocaine consumption, presented with a 5-day history of new-onset focal nonmotor dyscognitive epileptic events. After three days of treatment with oral phenytoin (PHT) $100 \mathrm{mg}$ t.i.d., a convulsive status epilepticus developed at the same time a third-degree atrioventricular block was registered (Figures 1 and 2).
As we know, cocaine consumption and PHT (specially in infusions $>50 \mathrm{mg} / \mathrm{min}$ or previous heart disease) are both related with adverse cardiovascular effects, specially arrhythmias ${ }^{1,2}$. Our case exemplifies the lethal combination of both, and the narrow neurological and cardiologic assessment of syncope versus epilepsy in patients with stereotypic paroxysmal episodes ${ }^{3.4}$.

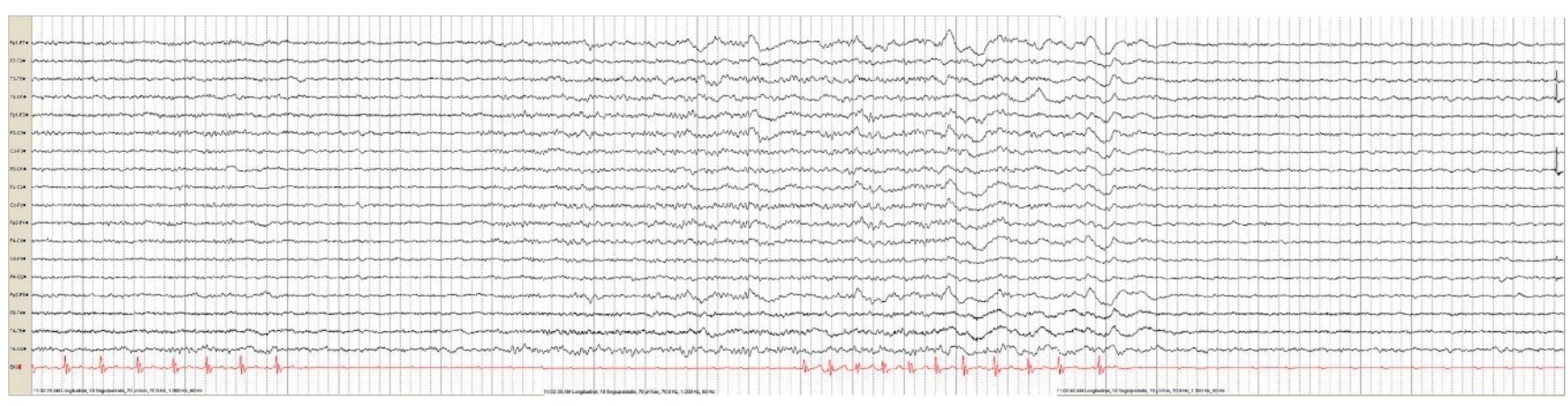

Figure 1. 6 consecutive epochs (11:02:28 to 11:03:28) are shown. Montage: Bipolar, longitudinal, double-banana. HF: 70 Hz,

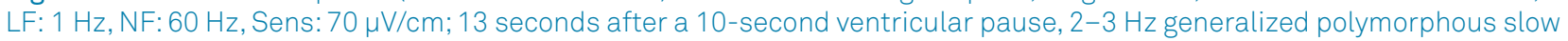
waves are registered with greater expression in the anterior regions. Following this, a new ventricular pause of 9 seconds appears, which will continue in the following figure.

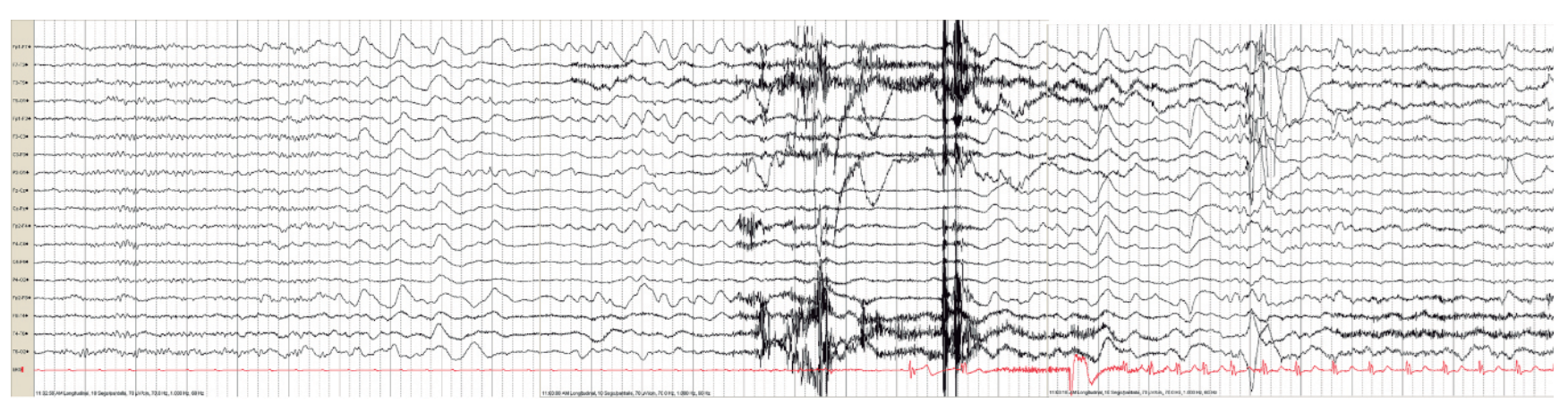

Figure 2. The last ventricular pause described in Fig. 1 continues for 17 more seconds (26 in total). Synchronous generalized slow waves are again registered. On the $24^{\text {th }}$ second, generalized electrodecrement with muscle artifact due to a generalized tonic seizure of 4 seconds of duration. This event ends with the recovery of the heart rhythm and subsequent slow waves in delta range before recovering its alpha rhythm.

\footnotetext{
${ }^{1}$ Hospital Psiquiátrico Infantil Juan N. Navarro, Unidad Psiquiátrica, México.

${ }^{2}$ Instituto Nacional de Neurología y Neurocirugía, Departamento de Neurología, México.

${ }^{3}$ Instituto Nacional de Neurología y Neurocirugía, Departamento de Neurofisiología, México.

Enrique GOMEZ-FIGUEROA (D) https://orcid.org/0000-0002-0206-322X; Roberto CERVANTES-URIBE (D) https://orcid.org/0000-0002-8014-3997

Correspondence: Enrique Gomez-Figueroa; Instituto Nacional de Neurología y Neurocirugía Manuel Velasco Suarez; Insurgentes Sur, 3877 ; Postal Code

14269; Tlalpan, Mexico City, Mexico; E-mail:enrique.g.figueroa@gmail.com

Conflict of interest: There is no conflict of interest to declare.
}

Received on August 14, 2019; Received in its final form on January 21, 2020; Accepted on February 12, 2020. 


\section{References}

1. Phillips K, Luk A, Soor GS, Abraham JR, Leong S, Butany J. Cocaine cardiotoxicity: a review of the pathophysiology, pathology, and treatment options. Am J Cardiovasc Drugs. 2009;9(3):177-96. https:// doi.org/10.2165/00129784-200909030-00005

2. Guldiken B, Rémi J, Noachtar S. Cardiovascular adverse effects of phenytoin.J Neurol. 2016;263:861-70. https://doi.org/10.1007/ s00415-015-7967-1
3. Ozkara C, Metin B, Kucukoglu S. Convulsive syncope: a condition to be differentiated from epilepsy. Epileptic Disord. 2009 Dec;11(4):315-9. https://doi.org/10.1684/epd.2009.0281

4. Díaz-Castro O, Orizaola P, Vázquez S, Gonzáles-Rios C, Pardo M, Fernández-López JÁ, et al. "Stokes-Adams Epilepsy” Sometimes We Need the Electroencephalogram. Circulation. 2005;112(8):e101-2. https://doi.org/10.1161/CIRCULATIONAHA.104.503144 